des Blutserums; schnellere Erstarrung und größere Un. abhängigkeit von äuBeren Schwankungen während der Erstarrung; gesteigerte Festigkeit und Elastizität; größere Wirtschaftlichkeit bei wenigstens gleiehwertiger Nährbodenqualität.

Aus dem Städtischen Untersuchungsamt für ansteckende Krankheiten in Charlottenburg.

\title{
Ein sparsamer Blutserumnährboden für die Diphtheriediagnose.
}

Von Dr. Hans Langer, Leiter des Amts.

Für die bakteriologisehe Diphtheriediagnose ist der Löfflersche Blutserumnährboden nach wie vor unübertroffen. Es hat bisher keiner der in neuerer Zeit angegebenen zahlreichen Nährböden bei gleich einfacher Verwendungstechnik die Kulturresultate des Löfflerserums erreichen können.

Es sei vorweggenommen, da $B$ im Nachstehenden nicht versucht worden ist, wiederum eine konkurrierende Nährbodenzusammenstellung anzugeben. Der Anla B zu dieser Mitteilung liegt vielmehr in dem Bedürfnis nach Sparsamkeit, in dem Wunsche, eine größere Ausnutzung des Nährboden materials zu erzielen.

Der Löfflersche Nährboden wird bekanntlich aus Rinder-, Hammeloder Pferdeblutserum hergestellt; aus äußeren Gründen benutzen wir Hammelserum, weil wir dieses auf dem Schlachthofe am ehesten steril und in größeren Mengen erhalten können. Bei großem Bedarf machen sich nun bisweilen Schwierigkeiten in der Beschaffung des nötigen Vorrats geltend; solche Schwierigkeiten könnten gelegentlich zu einer direkten Kalamität werden.

Zur Erzielung einwandfreier Löfflerplatten ist eine verhältnismäßig hohe Nührbodenschicht erforderlich. Bei Glasschalen mit $8 \mathrm{~cm}$ Durchmesser werden daher zur Herstellung einer Serumplatte ungefähr $15 \mathrm{ccm}$ Serumgemisch $\left({ }^{2} / 3\right.$ Hammelserum $+1 / 3$ Bouillon) verbraucht. Werden Platten mit weniger Material ausgegossen, so besteht die Gefahr, daß beim Erstarren des Serums eine Vertrocknung und Verkrustung eintritt, wodurch die Qualität des Nährbodens erheblich vermindert wird.

Der Wunsch, einerseits auf die als so hervorragend erkannten Löfflerplatten nicht verzichten zu müssen und anderseits eine möglichst große Ausnutzung zu erreichen, führte' zu der nachfolgenden Modifikation in der Herstellung der Platten. Die bei uns üblichen Petrischalen mit $8 \mathrm{~cm}$ Durchmesser werden mit etwa $10 \mathrm{ccm}$ eines $2 \%$ igen Wasseragars gefüllt (nit 0,5\% NaCl, ohne Fleischwasser, ohne Pepton). Nach dem Festwerden des Agar: wird auf diese Agarplatte die Löfflersche Serummischung in dünner Schicht aufgegossen. Es sind hierzu etwa $5 \mathrm{ccm}$ erforderlich. Die Platte wird nunmehr in den Erstarrungsapparat eingesetzt und bei von 70 auf $90^{\circ}$ steigender Temperatur zum Erstarren gebracht. Die Erstarrung ist nach durchschnittlich drei Stunden erreicht, während bei gleichem Verfahren die ïblichen Löfflerplatten wenigstens sechs Stunden erfordern. Nach dem Erstarren muß wegen der Verflüssigung des Agars die Platte vorsichtig herausgenommen werden. Mit der Abkühlung wird der Agar wieder fest, und man erhält so eine Kulturplatte, deren Oberfläche eine einwandfreie Blutserumplatte darstellt. Wir haben diesen Nährboden bereits an einem großen Material im Vergleich zur Original-Löfflerplatte geprüft und haben nicht nur eine völlige Gleichwertigkeit feststellen können, sondern sogar bisweilen eine direkte Ueberlegenheit in der Ueppigkeit des Wachstums. Die Gründe hierfür sind wohl darin zu suchen, daß infolge der durchwärmten Agarschicht eine gleichmäßigere Erhitzung des Blutserums eintritt, während bei der sonst üblichen Einfüllung durch die Wärmeleitung des Glases die Erstarrungstemperatur in den verschiedenen Schichten des Serums zu verschiedenen Zeiten erreicht wird. Ein weiterer Vorteil des Nährkodens liegt darin, daß trotz übereinstim. mender Konsistenz mit dem Löfflerserum eine größere Festigkeit und größere Elastizität erreicht wird und damit auch die Möglichkeit, das Untersuchungsmaterial gründlich zu verreiben, erhöht wird. Durch Anwendung dieser Nährbodenbereitung ergibt sich folgende Ersparnis: Für jede Platte werden anstatt $15 \mathrm{ccm}$ Blutserummischung nur $5 \mathrm{ccm}$ verbraucht, das bedeutet die dreifache Ausnutzung des Materials. Setzt man den Preis von 1 Liter Blutserummischung etwa mit 1,50 $\mathrm{M}$ an und die Bereitung von 1 Liter Wasseragar mit $0,15 \mathrm{M}$, so läßt sich ohne weiteres errechnen, daß die angegebene Bereitung der Blutserumplatte nicht nur zu einer ,,Streckung“ des Serums, sondern zu einer direkten Ersparnis führt.

Zusammenfassend ergibt sich als Vorteil der dargestellten Modifikation gegenüber der Löfflerplatte: Weitgehende Ausnutzung 